\title{
Approximating solutions of generalized pseudocontractive variational inequalities by admissible perturbation type iterative methods
}

\section{CRISTINA ŢICALĂ}

\section{ABSTRACT.}

In this paper we give the solvability class of generalized strongly nonlinear variational inequalities modified by the use of the new concept of admissible perturbation operator on nonempty closed convex sets in Hilbert spaces.

\section{REFERENCES}

[1] Berinde, V., Iterative Approximation of Fixed Points, Lecture Notes in Mathematics, Springer, 2007

[2] Berinde, V., Convergence theorems for fixed point iterative methods defined as admissible perturbations of a nonlinear operator, Carpathian J. Math., 29 (2013), No. 1, 9-18

[3] Berinde, V., Khan, A. R. and Fukhar-ud-din, H., Fixed point iterative methods defined as perturbations for generalized pseudocontractive operators (submitted)

[4] Berinde, V., Măruşter, Şt. and Rus, I. A., An abstract point of view of iterative approximation of fixed points of nonself operators, J. Nonlinear Convex Anal. (accepted)

[5] Berinde, V., Khan, A. R. and Păcurar, M., Convergence theorems for admissible perturbations of $\varphi$ - pseudocontractive operators, Miskolc Math. Notes, 15 (2014), No. 1 (in print)

[6] Browder, F. E. and Petryshyn, W. V., Construction of fixed points of nonlinear mappings in Hilbert spaces, J. Math. Anal. Appl., 20 (1967), 197 - 228

[7] Glowinski, R., Numerical Methods for Nonlinear Variational Problems, Springer - Verlag, New York, 1984

[8] Glowinski, R., Lions, J. L. and Tremolieres, R., Numerical Analysis of Variational Inequalities, 8. North-Holland Publishing Co., Amsterdam-New York, 1981

[9] Kinderlehrer, D. and Stampacchia, G., An Introduction to Variational Inequalities and their Applications, Academic Press, New York, 1980

[10] Kirk, W. A., Remarks on pseudo-contractive mappings, Proc. Amer. Math. Soc., 25 (1970), 821 - 823

[11] Moloney, J, and Weng, X., A fixed point theorem for demicontinuous pseudocontractions in Hilbert space, Studia Math., 116 (1995), No. 3, 217 - 223

[12] Noor, M. A., Generalized auxiliary principle for variational inequalities, PanAmerican Math. J., 4 (1994), No. 1, 27 - 44

[13] Petryshyn, W. V., Nonlinear equations involving noncompact operators, In: Nonlinear Functional Analysis, Proc. Sympos. Pure Math., (F. E. Browder, ed.), Amer. Math Soc. Providence, 1970, 206 - 233

[14] Rus, I. A., An abstract point of view on iterative approximation of fixed points, Fixed Point Theory, 33 (2012), 179-192

[15] Siddiqi, A. H and Ansari,Q. H, Strongly nonlinear quasivariational inequalities, J. Math. Anal. Appl., 149 (1990), $444-450$

[16] Verma, R. U., General approximation - solvability of nonlinear equations involving A-regular operators, Zeitschrift Anal. Anwendungen, 13 (1994), $89-96$

[17] Verma, R. U., Nonlinear variational and constrained hemivariational inequalities involving relaxed operators, ZAMM, 77 (1997), 387 - 391

[18] Verma, R. U., Strongly nonlinear variational Inequalities and generalized pseudocontractions, Rend. Circ. Mat. Palermo, 48 (1999), No. 2, 201 - 208

DePARTMENT OF MATHEMATICS AND COMPUTER SCIENCE

Faculty of Sciences North University Center at Baia Mare

TECHNICAL UNIVERSITY OF CLUJ-NAPOCA

VICTORIEI 76, 430122 BAIA MARE, ROMANIA

E-mail address: cristina.ticala.popegmail.com

* Dedicated to Professor Emeritus Constantin Corduneanu on the occasion of his 85th birthday

Received: 15.08.2013; In revised form: 25.09.2013; Accepted: 28.09.2013

2010 Mathematics Subject Classification. 47H10, 35M86.

Key words and phrases. Fixed point, admissible perturbation. 